\title{
The Dawning of a New Decade
}

$\mathbf{T}$ his issue kicks off our 10th year of publication! In the first issue in February 1999, J. Sloan Manning, M.D., the Companion's founding editor, described the journal's intended purpose as bringing to our readers peer-reviewed psychiatric research relevant to primary care "that involves clinical practice or has the potential to be translated into patient care in a way that improves our understanding of illness and the quality of our practices." ${ }^{(\mathrm{p} 3)}$ This remains our charge. Over the intervening years, and especially in the last 2 to 3 years, we have seen a significant uptick in the number of manuscripts submitted and the quality of research pertaining to primary care and psychiatry.

In his inaugural editorial, Dr. Manning went on to describe his own journey in becoming effective in treating psychiatric illness presenting in his family practice (and to those of us who know him, Dr. Manning is the master clinician). This included overcoming the deficiencies related to his residency training with its "limited exposure to psychiatrists who practiced effective psychopharmacology in favor of interactions with nonphysicians whose philosophies neither stressed inherited biological vulnerability nor modeled such interventions."1(p4) Dr. Manning described experiences common to many of us, including the joy of seeing a previously chronically depressed dysthymic woman emerge into full remission following a treatment experiment (despite his residency education that dysthymia is untreatable) and the perplexing lack of response or worsening of patients whose bipolar disorder had been misdiagnosed.

In the intervening decade, we have seen major advances in the engagement of primary care physicians with the psychiatric aspects of their patients. In June 2002, the United States Preventive Services Task Force changed its previous negative recommendation and endorsed screening for major depression in primary care, with the caveat that practices must be able to actively manage those who screen positive. Depression screening and treatment have since become common metrics of quality of care for many health systems. The National Institute of Mental Healthsponsored Sequenced Treatment Alternatives to Relieve Depression (STAR*D) study enforced our understanding of the need and effectiveness of active management. We have weathered the major setback of the "black-box warning" epidemic and the remarkable increase in completed suicides that ensued this public health fiasco. The scope of psychiatric care competently provided by informed primary care physicians has also greatly broadened over the decade to include the anxiety disorders, bipolar disease in its numerous manifestations, attention- deficit/hyperactivity disorder, substance abuse, and dementing illness including Alzheimer's disease. This expansion of the scope of primary care practice has been fostered by the increasing availability of effective pharmacologic agents as well as advances in our understanding of evidence-based psychotherapies.

Our understanding of the biological basis of psychiatric disorders also has advanced at a rapid pace, with much information of direct relevance to primary care practice. The biological underpinning of psychiatric illness deemphasized in Dr. Manning's residency is now an intellectual tour de force, advancing our basic conceptualization of illness and the illness experience and offering treatments with remarkable potential. Our increased understanding of the biological basis of psychiatric disease also is rewriting textbooks, with a fundamental restructuring of our understanding of the relationship of "organic" illness-such as diabetes, cardiac disease, and other chronic illnesses — and psychiatric illness and underlying brain processes. Perhaps the most important advance of the past decade from a primary care perspective is that our patients are not depressed because they have these medical illnesses. Instead, they may have developed their cardiac disease because they have lived with untreated depressive illness and anxiety. A fuller lifespan understanding of these disease processes begins with their genetic predispositions (e.g., serotonin transporter and norepinephrine genes), the impact of early life experiences, and ongoing supports and stresses. These influences very likely result in brain processes that not only cause the psychiatric symptoms we see in our patients, but also set in motion pathophysiologic processes that lead to chronic medical illness and vulnerabilities. Given this emerging understanding, ignoring or minimizing psychiatric illness and its biological basis is no longer an option in medicine. To do so is simply bad medicine, even when the presenting complaints are deemed to be purely somatic.

In looking ahead, the Companion will continue to bring relevant research and evidence-based synthesis of research to support our readers in staying current and improving their practices. The next decade is likely to see advances even more remarkable than those of the past decade. Genetic advances may lead to practical tools for practice. For example, the HTR2A gene may serve as a biomarker of patients who will respond positively to serotonin-based antidepressant treatment; the Bcl-2 gene may identify (as it did in the STAR*D analyses) patients highly likely to attain full remission with treatment. Other biomarkers may become available to guide treatment of bipolar disease, psychotic illness, and substance abuse. 
Other brain research is likely to redefine our diagnostic constructs and lead to biological-based diagnostic procedures. Health services research and information technology advances are likely to improve our primary carebased capacity to actively manage patients with psychiatric illness, including over the long term. Continued documentation of the importance of psychiatric illness in influencing the outcomes of comorbid chronic medical illness and the definitive demonstration of the disease-modifying benefit of psychiatric treatment in such patients are likely to advance the acceptance of and access to such treatment. At one end of life, the role of psychiatric illness and maternal brain processes in prematurity and birth outcomes, and, at the other end of life, the role of psychiatric care in sustaining a high functioning existence are likely to become of great importance to those of us in primary care and to our patients. In all of these areas, the Companion will be a source of information as new discoveries impact primary care.

We will continue to evolve the content and format of the Companion, in keeping with the state of the field. For instance, primary care of psychiatric and brain disease in those advancing in years has been relatively ignored until recently. However, to encourage and to reflect the increasing attention being paid to this group, we will highlight such work in the Companion, as will be announced in an upcoming issue.

As we move into our second decade, we want to extend appreciation to those of you who value the Companion by being part of our readership, those authors who create and submit the content to the Companion, and to our reviewers, many of whom have put in numerous hours over the years providing the critique that improves manuscripts and assures the quality of the journal. We especially thank and acknowledge those who reviewed the largest volume of manuscripts over the past year in this year's Circle of Honor. Thank you!

\section{REFERENCE}

1. Manning JS. Welcome! Why this journal? Prim Care Companion J Clin Psychiatry 1999;1:3-4

Larry Culpepper, M.D., M.P.H. Editor in Chief

\section{The Primary Care Companion TO THE JOURNAL OF CLINICAL PSYCHIATRY}

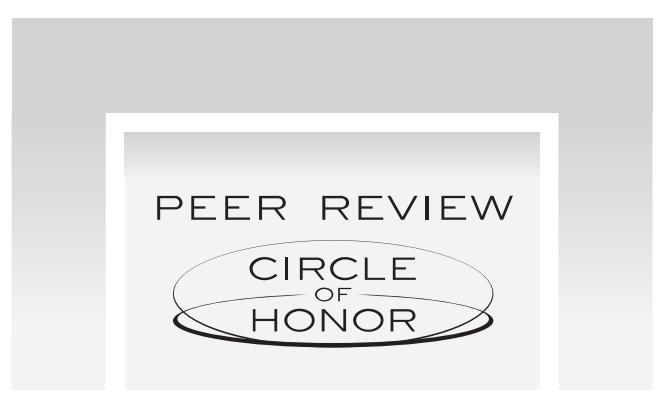

Stephen Adams, M.D.

E. Sherwood Brown, M.D., Ph.D.

Pamela D. Connor, Ph.D.

Frank DeGruy, M.D.

Daniel E. Diamond, M.D.

Donna B. Greenberg, M.D.

Joseph A. Lieberman III, M.D.
J. Sloan Manning, M.D.

Don E. Nease, M.D.

Mark H. Pollack, M.D.

Michael E. Thase, M.D.

Bryan K. Touchet, M.D.

L. Lee Tynes, M.D., Ph.D.

William R. Yates, M.D. 


\section{Reviewers for \\ The Primary Care Companion to the Journal of Clinical Psychiatry January 1, 2007-December 31, 2007}

Charles Abaaba, M.D.

Giovanni Addolorato, M.D.

Niraj Ahuja, M.D., M.R.C.Psych.

Hagop S. Akiskal, M.D.

Michael Allen, M.D.

Jay D. Amsterdam, M.D.

Jules Angst, M.D.

Ralph Aquila, M.D.

Denise Saint Arnault, Ph.D., R.N.

Stephen Atlas, M.D.

Ashley Benjamin, M.D.

Timothy Berigan, D.D.S., M.D.

Srikala Bharath, M.D., M.R.C.Psych., D.P.M., D.C.A.P.

Lars Bjerrum, M.D.

Ulrike Buhlmann, Ph.D.

Alexander Bystritsky, M.D.

Paul Carey, M.Med. (Psych)

Jennifer Carroll, M.D.

Mesut Cetin, M.D.

Sunday Clark, Dr.P.H.

Humberto Corrêa, M.D., Ph.D.

Jeffrey A. Cully, Ph.D.

John M. Davis, M.D.

Giovanni Defazio, M.D.

Gretchen J. Diefenbach, Ph.D.

Paul P. Doghramji, M.D., F.A.A.F.P.

Milton K. Erman, M.D.

John Finney, Ph.D.

Brent Forester, M.D.

Andrea Fossati, M.D.

Jennifer L. Francis, Ph.D.

Bradley N. Gaynes, M.D., M.P.H.
Jean Gehricke, Ph.D.

Vinu George, M.D.

Anne Germain, Ph.D.

Rachel Glick, M.D.

Jean-Louis Goeb, M.D.

Jack Gorman, M.D.

Richard C. W. Hall, M.D.

Byung-Joo Ham, M.D., Ph.D.

Elie G. Hantouche, M.D.

Kenji Hashimoto, Ph.D.

Alison M. Heru, M.D.

Todd F. Holzman, M.D.

Rachael R. Irving, Ph.D.

Mohan Isaac, M.D.

Philip G. Janicak, M.D.

Anita S. Kablinger, M.D.

Craig H. Kennedy, Ph.D.

Amy M. Kilbourne, Ph.D., M.P.H.

Rikus Knegtering, M.D., Ph.D.

Susan G. Kornstein, M.D.

Kurt Kroenke, M.D.

Si-Chen Lee, Ph.D.

Sid Lerfald, M.D.

Stefan Leucht, M.D.

Maria Mancebo, Ph.D.

Suresh Bada Math, M.D., D.N.B., P.G.D.M.L.E.

John McCabe, M.D.

Lisa J. McGarry, M.P.H.

Lachlan McWilliams, Ph.D.

Christian Mille, M.D.

Daniel J. Muller, M.D.
Pratima Murthy, D.P.M., M.D.

Rosemary Nourse, R.N.

Paul Nutting, M.D.

John M. Oldham, M.D.

Peter Osvath, M.D., Ph.D.

Koichi Otani, M.D.

Michael L. Perlis, Ph.D.

Giulio Perugi, M.D.

Frederick D. Petty, Ph.D., M.D.

Wilfred R. Pigeon, Ph.D.

Sriram Ramaswamy, M.D.

Hugh Rickards, M.D.

Matthias W. Riepe, M.D.

Muhamad Aly Rifai, M.D.

Randy A. Sansone, M.D.

Leonard J. Schmidt, M.D.

Frederick A. Schmitt, Ph.D.

Thomas L. Schwartz, M.D.

Thomas L. Schwenk, M.D.

Hideto Shinno, M.D.

George M. Simpson, M.D.

Paul E. Stang, Ph.D.

Jonathan W. Stewart, M.D.

Jørund Straand, M.D., Ph.D.

Antonio L. Teixeira, M.D., Ph.D.

Marshall Thomas, M.D.

Risa B. Weisberg, Ph.D.

John W. Williams, Jr., M.D.

Thomas N. Wise, M.D.

Lawson R. Wulsin, M.D.

Grace Wyshak, Ph.D., M.S. Hyg.

Robert G. Zylstra, Ed.D., L.C.S.W. 